УДК 633.491: 631.559.2

06.01.01 Общее земледелие, растениеводство

РОСТ И РАЗВИТИЕ РАННЕГО КАРТОФЕЛЯ
В ЗАВИСИМОСТИ ОТ ФОНА ПИТАНИЯ И
СПОСОБОВ ПРИМЕНЕНИЯ СТИМУЛЯТОРА
РОСТА БЕРЕКЕ ГН В УСЛОВИЯХ ЮГА
КЫРГЫЗСТАНА

Танаков Нурланбек Токтогулович кандидат сельскохозяйственных наук, доцент РИНЦ SPIN-код: 7938-1115, AuthorID: 910995 ntanakov@bk.ru

Ирматова Жылдыз Камиловна кандидат технических наук, доцент РИНЦ SPIN-код: 6926-8038, AuthorID: 921494 julduz75@mail.ru

Саипова Аида Шарабидиновна преподаватель кафедры технологии переработки сельскохозяйственной продукции saipova79@mail.ru

Жантураева Барна Турдалиевна магистр, старший преподаватель кафедры технологии переработки bganturaeva@mail.ru

Ошский технологический университет имени академика М.М. Адышева, г. Ош, Кыргызская Республика

В условиях юга Кыргызстана изучено рост и развитие раннего картофеля в зависимости от фона питания и способов стимулятора роста Береке ГН с целью повышения урожайности и качества картофеля. Научные исследование влияния стимуляторов роста на картофель на продуктивность раннего картофеля в условиях юга Кыргызстана не проводились. Полевые опыты проведены на опытном участке Ошского технологического университета в селе Мангыт Араванского района Ошской области Кыргызской Республики в 2016-2018 гг. При повышении фона питания, в разрезе опытов по способам применения стимулятора роста Береке ГН в фазах развития растений раннего картофеля были замечены закономерные отличия по вариантам. В повышенном фоне питания выявлено повышение продолжительности межфазных периодов. Во все годы проведения опытов в варианте комплексное применение стимулятора роста, соответственно повышенных фонах питания образовались зеленые, толстые и крепкие ростки длиной 1,5-2,1мм. А также комплексное применение стимулятора роста способствовала ускоренному появлению всходов. По данным результатов наших исследований, мы выявили зависимость сохранности растений к
UDC 633.491: 631.559.2

General agriculture and crop production

\section{GROWTH AND DEVELOPMENT OF EARLY POTATOES DEPENDING ON THE BACKGROUND OF NUTRITION AND WAYS OF USING THE GROWTH STIMULANT BERKE MR. IN THE CONDITIONS OF SOUTHERN KYRGYZSTAN}

Tanakov Nurlanbek Toktogulovich

Candidate of Agricultural Sciences

RSCI SPIN- code: 7938-1115, AuthorID: 910995

ntanakov@bk.ru

Irmatova Zhyldyz Kamilovna

Candidate of Technical Sciences, Associate Professor RSCI SPIN code: 6926-8038, AuthorID: 921494 julduz75@mail.ru

Saipova Aida Sharabidinova

Lecturer of the Department of Agricultural Processing Technology

saipova79@mail.ru

Zhanturayeva Barna Turdaliyevna

Master, Senior lecturer of the Department of

Agricultural Processing Technology

bganturaeva@mail.ru

Osh Technological University named after

academician M. M. Adyshev, Osh, Kyrgyz Republic

In southern Kyrgyzstan, the growth and development of early potatoes has been studied, depending on nutrition background and the methods of growth stimulant Bereke GN, aiming to improve the yield and quality of potatoes. There were no scientific studies on growth stimulants impacts on potatoes, the productivity of early potatoes in southern Kyrgyzstan conducted. Field experiments were carried out on the experimental site of the Osh Technological University in the Kyrgyz Republic Osh region Aravan district Mangyt village in 2016-2018. In case of increasing the nutrition background, in terms of experiments on methods of using the growth stimulant Bereke GN in the phases of development of early potato plants, natural differences in variants were observed. Increased duration of interfacial periods is detected in increased power supply background. In all years of experiments in the variant complex application of growth stimulator, respectively increased nutrition backgrounds, green, thick and strong sprouts of 1.5-2.1 mm length were formed. As well as complex use of growth stimulant contributed to accelerated emergence of sprouts. According to the results of our research, we have identified the dependence of plant preservation on harvesting from the application of fertilizers and the method of use of 
уборке от внесения удобрений и способа применения стимулятора роста. Следовательно, при комплексном применении стимулятора роста Береке ГН на посевы раннего картофеля наблюдались повышение количество сохраненных растений к уборке раннего картофеля на 0,7-1,6\%, при обработке стимулятором роста семенных клубней на 0,3-0,6 \%, при распылении листьев на $0,1-0,3 \%$

Ключевые слова: РАННИЙ КАРТОФЕЛЬ, СОРТ, ФОН ПИТАНИЯ, СТИМУЛЯТОР РОСТА, СТЕБЕЛЬ, РОСТ, РАЗВИТИЕ, УРОЖАЙНОСТЬ growth stimulant. Consequently, with the complex application of Bereke GN growth stimulant to early potato crops, there was an increase in the number of preserved plants for early potato harvesting by 0.7 $1.6 \%$, with seed tuber growth stimulant treatment by $0.3-0.6 \%$, and with leaf spraying by $0.1-0.3 \%$

Keywords: EARLY POTATOES, VARIETY, FOOD BACKGROUND, GROWTH STIMULATOR, STEM, GROWTH, DEVELOPMENT, YIELD

DOI: http://dx.doi.org/10.21515/1990-4665-153-020

Введение. В условиях Кыргызстана более высокое преобладание азота в комплексе удобрений приводит к ухудшению качества клубней. Поэтому применение повышенных доз азота при удобрении картофеля нежелательно. Большое внимание в хозяйствах должно уделяться совместному внесению под ранний картофель органических и минеральных удобрений. Однако органическое удобрение не обеспечивает того увеличения урожая, которое получается при совместном его внесении с минеральными удобрениями [1].

В некоторых странах средней части Европы и России, в том числе и у нас в Кыргызстане, агроэкологические условия не позволяют выращивать картофель в течение круглого года. Но несмотря на эти данные производить в достаточном количестве свежий картофель в нашей республике со первой декады мая до начала июня вполне возможно. Для выполнения такой задачи требуется соблюдать некоторые особенности технологии производства раннего картофеля [2, 3].

Самые высокие урожаи раннего картофеля получают при внесении комплексного удобрения и компостов с различными способами. В опытах КыргНИИЗ на обыкновенных сероземах Чуйской долины более высокий урожай раннего картофеля получен при внесении полного минерального удобрения с небольшим преобладанием азота [4]. 
Исследование влияния фона питания и способов применения стимуляторов роста на урожай картофеля в условиях юга Кыргызстана не проводились. Таким образом, в связи с отсутствием дифференцированных норм внесения удобрений и недостаточности данных о влияния стимуляторов роста на ранний картофель, мы сочли целесообразным проводить исследования. В условиях юга Кыргызстана подобные исследования в технологии производства раннего картофеля проводятся впервые.

Цель исследований - изучить влияние фона питания и способы применения стимулятора роста на урожайность и качество раннего картофеля в условиях юга Кыргызстана.

Материалы и методика проведенных исследований. Полевые опыты по влиянию удобрений и различных способов применения стимулятора роста Береке ГН на продуктивность раннего картофеля в условиях юга Кыргызстана проводили в 2016-2018 гг. Выбрали раннеспелый сорт Марабелл. Посадку раннего картофеля проводили в 2016 году 6 марта, в 2017 - 12 марта и в 2018- 20 марта.

Опыты закладывались на типичных сероземах, легкосуглинистых и легких суглинках, слабозасоленных почвах, с содержанием гумуса от 1,71 до $1,85 \%$, с низкой обеспеченностью общим азотом 0,9-08\%, средней фосфором 4,13-4,16мг на 100г почвы и калием 47,5-49,8мг на 100г почвы. Реакция почвенной среды близка к нейтральной, $\mathrm{pH}=7,5$. В составе солей сульфаты преобладают над хлоридами.

Общая площадь делянки $72 \mathrm{~m}^{2}$, учетная - $56 \mathrm{~m}^{2}$. Размещения вариантов опыта последовательно. Повторность трехкратная. Предшественник - кукуруза на силос. Глубина посадки клубней 6-8см. При посадке использовали клубни средней фракции (50-80 г). Густота посадки 55,0 тыс. клубней на 1 гектар.

Схема опыта двухфакторный: Фактор А: 1. Без внесения удобрения; 
2. Расчет на урожайность 30 т/га клубней (навоз 30 т/га $+\mathrm{N}_{115} \mathrm{P}_{90} \mathrm{~K}_{120}$ ); Фактор В: 1. Контроль (вода); 2. Обработка семенных клубней стимулятором роста перед посадкой (замачивание на 6-8 часов); 3 . Применение стимулятора роста в фазах всходы и бутонизация (распыление листьев); 4. Комплексное применение стимулятора роста (замачивание клубней + распыление листьев двукратно).

Приготовление рабочих растворов: Раствор 1- для корневой подкормки и замачивания семян 100 мл Береке ГН растворяют в 10 л воды; Раствор 2- для корневой и некорневой подкормки 30 мл Береке ГН растворяют в 10 л воды. Обработка семенных клубней - замочить клубни на 6-8 часов в растворе 1. Корневая подкормка и не корневая обработка (распыление листьев) - после появления листьев поливать или распылять растворами 1,2. Норма расхода 7-10 л на $10 \mathrm{~m}^{2}$.

Обрабатывали семенных клубней (замачивание) перед посадкой, расход рабочего раствора 200 л/т и доза стимулятора роста составил 2000 мл/т. Опрыскивали в фазе всходы и бутонизации, расход 300 л/га, доза составил 900 мл/га.

Закладка опытов, анализы, учеты и наблюдения проводились в соответствие с общепринятыми методиками. Математическую обработку данных осуществляли методом дисперсионного анализа с расчетом вклада фактора в общую вариацию признака $[5,6,7,8]$. Почвенные анализы, выполнены по Агрохимическим методам исследования почв $[9,10]$.

Результаты исследований. По данным исследований можем анализировать что, при комплексной применении и при обработке клубней семенного материала стимулятором роста Береке ГН заметно влияют на рост и развитие, а также на прохождение фенологических фаз растений.

$\mathrm{C}$ повышение фона питания, поставленных опытных вариантах при применении стимулятора роста в фазах развития растений раннего картофеля были видны различные отличия по вариантам. В повышенных 
фонах питания выявлено закономерное увеличение продолжительности межфазных периодов (рис. 1, 2, 3).

Во все годы исследования в опытах при комплексном применении стимулятора роста и повышенных фонах питания образовались зеленые, толстые и крепкие ростки длиной 1,5-2,1мм. Комплексное применение стимулятора роста способствовала ускоренному появлению всходов.

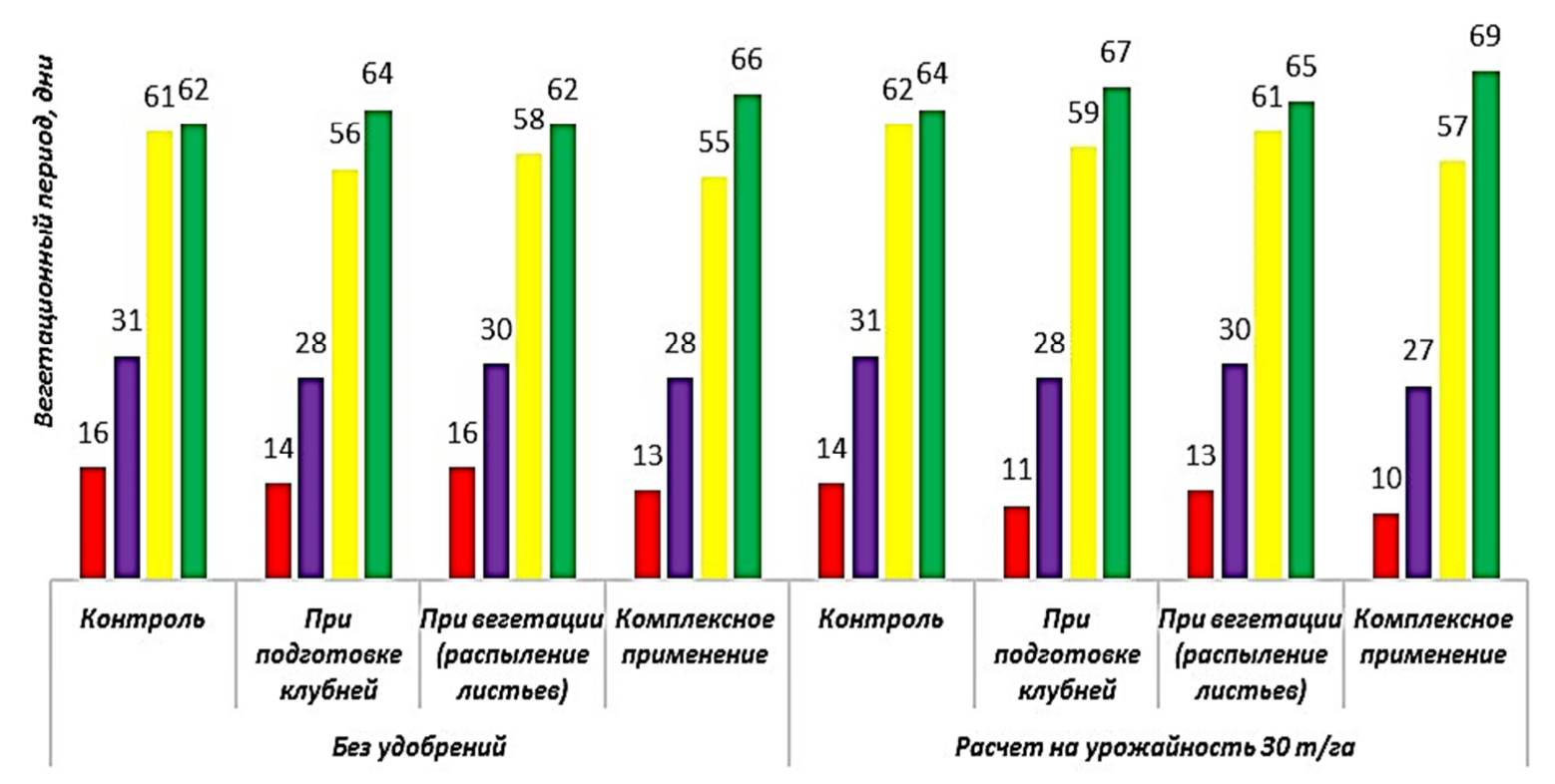

घ Посадка-всходы $\square$ Всходы-цветение $\square$ Всходы-нач. отм. ботвы घ Всходы-уборка

Рисунок-1 Динамика продолжительности межфазных периодов в зависимости от фона питания и способов применения стимулятора роста Береке ГН (гумат натрия), 2016 год 


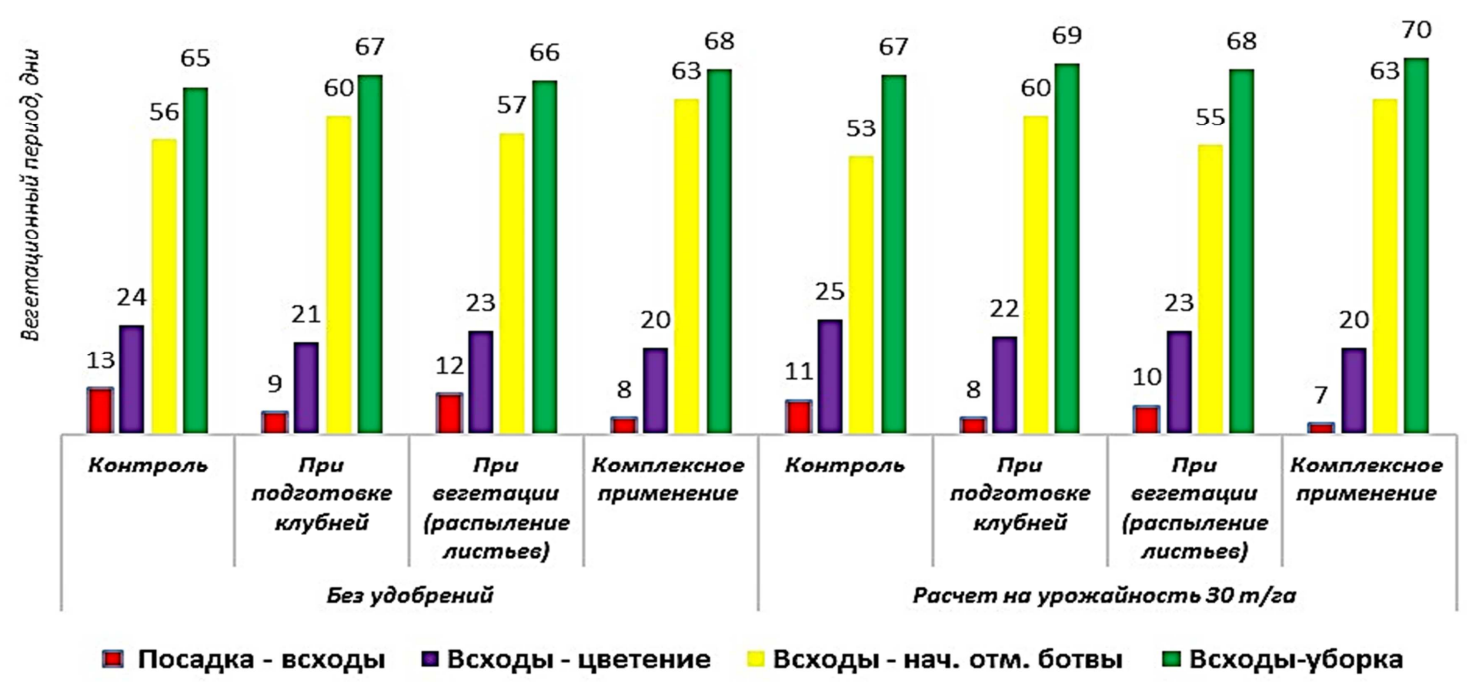

Рисунок-2 Динамика продолжительности межфазных периодов в зависимости от фона питания и способов применения стимулятора роста Береке ГН (гумат натрия), 2017 год

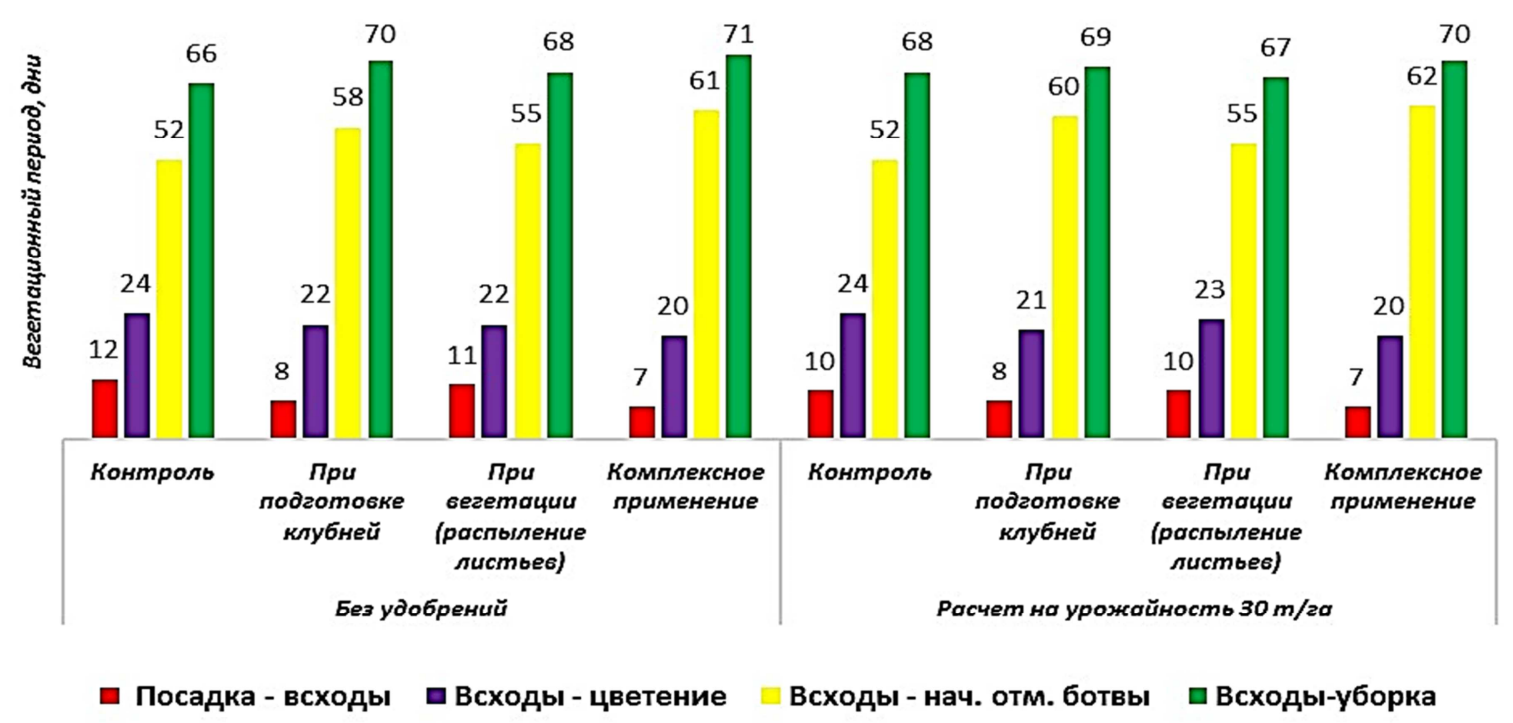

Рисунок-3 Динамика продолжительности межфазных периодов в зависимости от фона питания и способов применения стимулятора роста Береке ГН (гумат натрия), 2018 год

За три года проведения опытов в вариантах с повышенным фоном питания при комплексной обработке регулятором роста привело к ускорению появлению всходов в среднем на 4-6 дней, при обработке клубней на 2-4 дней. В дальнейшем на этих опытных вариантах и на 
повышенных фонах питания наблюдалось опережение наступления фенологических фаз.

При комплексном применении стимулятора роста цветение растений раннего картофеля в зависимости от исследуемого года наступало на 1114, 9-7 и 1-2 дня раньше. В 2016 году разница между вариантами опыта в фазе начало отмирания ботвы составила 1-4, в 2017 году 1-6, а в 2018 году 1-2 дня.

За три года проведения опытов ботва растений раннего картофеля в фазе «уборка» была зеленной, и отмечалось частичное отмирание ботвы. Таким образом, при возделывании раннего картофеля при повышенных фонах питания уборку можно проводить в более поздние сроки.

Для повышения продуктивности раннего картофеля важную роль играет оптимальное количество растений на единицу площади. А также наибольшее значение имеет количество стеблей на единице площади. Количество растений зависит от густоты посадки, которая определяется количеством посаженных клубней, агротехническими условиями и фоном питания.

В вегетационном периоде растений раннего картофеля, достигая оптимальной густоты стояния растений, можно сформировать урожай с различной продуктивностью. По данным наших исследований отмечается влияние повышенного фона питания, при различных вариантах опытов по применении стимулятора роста на сохранность растений раннего картофеля. (табл.4).

Таблица 4 - Густота стояния и сохранность растений раннего картофеля в зависимости от фона питания и способов применения стимулятора роста Береке ГН (гумат натрия) (2016-2018 гг.)

\begin{tabular}{|c|c|c|c|c|c|c|}
\hline \multirow[b]{2}{*}{ Варианты } & \multicolumn{2}{|c|}{ Всходы } & \multicolumn{2}{|c|}{ Цветение } & \multicolumn{2}{|c|}{ Уборка } \\
\hline & $\begin{array}{c}\text { количество } \\
\text { всхожих } \\
\text { растений, } \\
\text { тыс. куст/га }\end{array}$ & $\begin{array}{c}\text { всхо- } \\
\text { жесть, } \\
\%\end{array}$ & \begin{tabular}{|c|} 
количество \\
растений, \\
тыс. куст/га
\end{tabular} & $\begin{array}{c}\text { \% от } \\
\text { взошед- } \\
\text { ших }\end{array}$ & $\begin{array}{c}\text { количество } \\
\text { растений, } \\
\text { тыс. куст/га }\end{array}$ & $\begin{array}{c}\text { сохран- } \\
\text { ность, } \\
\%\end{array}$ \\
\hline \multicolumn{7}{|c|}{ Без удобрений } \\
\hline
\end{tabular}




\begin{tabular}{|c|c|c|c|c|c|c|}
\hline Контроль & 51,4 & 93,4 & 49,3 & 96,0 & 47,9 & 93,2 \\
\hline $\begin{array}{c}\text { При подготовке } \\
\text { клубней }\end{array}$ & 52,2 & 94,9 & 50,3 & 96,4 & 48,7 & 93,3 \\
\hline $\begin{array}{c}\text { При вегетации } \\
\text { (распыление листьев) }\end{array}$ & 51,5 & 93,7 & 49,8 & 96,6 & 48,2 & 93,5 \\
\hline $\begin{array}{c}\text { Комплексное } \\
\text { применение }\end{array}$ & 53,2 & 96,8 & 51,8 & 97,3 & 50,4 & 94,7 \\
\hline \multicolumn{7}{|c|}{ Расчет на урожайность 30 т/га } \\
\hline Контроль & 51,6 & 93,8 & 49,8 & 96,6 & 48,3 & 93,7 \\
\hline $\begin{array}{c}\text { При подготовке } \\
\text { клубней }\end{array}$ & 52,4 & 95,3 & 50,9 & 97,1 & 49,5 & 94,5 \\
\hline $\begin{array}{c}\text { При вегетации } \\
\text { (распыление листьев) }\end{array}$ & 51,8 & 94,2 & 50,1 & 96,7 & 48,8 & 94,3 \\
\hline $\begin{array}{c}\text { Комплексное } \\
\text { применение }\end{array}$ & 53,6 & 97,4 & 52,3 & 97,6 & 51,2 & 95,6 \\
\hline
\end{tabular}

При комплексном применении регулятора роста, а также при обработке стимулятором семенного материала раннего картофеля наблюдалось повышение всхожести растений. Точнее, при комплексной применении регулятора роста повысилось количество всходов на 2,9-3,5\%, при обработке семенного материала $-1,3-1,7 \%$, при распылении листьев 0,3-0,6\%, по сравнению с вариантом без обработки.

Анализируя результаты наших исследований, мы выявили зависимость сохранности растений к уборке от внесения удобрений и способа применения стимулятора роста. Точнее, при комплексном применении стимулятора роста в повышенном фоне питании наблюдалось повышение количество сохраненных растений к уборке раннего картофеля на 0,7-1,6\%, при обработке стимулятором роста семенных клубней на 0,3$0,6 \%$, при распылении листьев на $0,1-0,3 \%$.

Выводы. В вариантах исследований без внесения удобрений и повышенных фонах питания при исследовании различных способов применение стимулятора роста Береке ГН было выявлено более ранние всходы и дружное цветение. При комплексной применении регулятора роста повышалось количество всходов на 2,9-3,5\%, при обработке 
семенного материала -1,3-1,7\%, при распылении листьев - 0,3-0,6\%, по сравнению с вариантом без обработки.

Выявлено зависимость сохранности растений к уборке от внесения удобрений и способа применения стимулятора роста. При комплексном применении стимулятора роста в повышенном фоне питании наблюдалось повышение количество сохраненных растений к уборке раннего картофеля на 0,7-1,6\%, при обработке стимулятором роста семенных клубней на 0,30,6\%, при распылении листьев на 0,1-0,3\%.

\section{Список литературы}

1. Научно обоснованная система земледелия Ошской области Киргизской ССР / Министерство сельского хозяйства Кирг. ССР, Кирг НПО по земледелию, Кирг. НИИ пастбищ и кормов, Кирг. НИИ почвоведения; под ред. М. Р. Райымкулова и др.Фрунзе.: - Кыргызстан, 1984. - 328 с.

2. Писарев, Б. А. Производство раннего картофеля / Б.А. Писарев. - М.: Россельхозиздат, 1986. -287c.

3. Рекомендации по выращиванию раннего картофеля в Киргизской ССР. Фрунзе: Киргизское научно-производственное объединение по земледелию, 1979. -21 с.

4. Рекомендации по выращиванию семенного картофеля в Киргизии. Фрунзе: Киргизское научно-производственное объединение по земледелию, 1989. -37 с.

5. Доспехов, Б. А. Методика полевого опыт / Б. А. Доспехов. - М.: Агропромиздат, 1985. - 351 с.

6. Методика исследований по картофелю. - М., 1967. - 263 с.

7. Методика исследований по культуре картофеля. - М.: Россельхозиздат, 1986. $45 \mathrm{c}$.

8. Методика Государственного сортоиспытания сельскохозяйственных культур. Вып. 2, М.: Колос, 1971. 189 с.

9. Агрохимические методы исследования почв. - М.: Наука, 1975. - 656 с.

10. Аринушкина, Е.В. Руководство по химическому анализу почв / Е. В Аринушкина. - М.: Изд-во МГУ, 1970. - 487 с.

\section{References}

1. Nauchno obosnovannaja sistema zemledelija Oshskoj oblasti Kirgizskoj SSR / Ministerstvo sel'skogo hozjajstva Kirg. SSR, Kirg NPO po zemledeliju, Kirg. NII pastbishh i kormov, Kirg. NII pochvovedenija; pod red. M. R. Rajymkulova i dr.- Frunze.: - Kyrgyzstan, 1984. - $328 \mathrm{~s}$.

2. Pisarev, B. A. Proizvodstvo rannego kartofelja / B.A. Pisarev. - M.: Rossel'hozizdat, 1986. $-287 \mathrm{~s}$.

3. Rekomendacii po vyrashhivaniju rannego kartofelja v Kirgizskoj SSR. Frunze: Kirgizskoe nauchno-proizvodstvennoe ob\#edinenie po zemledeliju, 1979. -21 s.

4. Rekomendacii po vyrashhivaniju semennogo kartofelja v Kirgizii. Frunze: Kirgizskoe nauchno-proizvodstvennoe ob\#edinenie po zemledeliju, 1989. -37 s. 
5. Dospehov, B. A. Metodika polevogo opyt / B. A. Dospehov. - M.: Agropromizdat, 1985. $-351 \mathrm{~s}$.

6. Metodika issledovanij po kartofelju. - M., 1967. - $263 \mathrm{s.}$

7. Metodika issledovanij po kul'ture kartofelja. - M.: Rossel'hozizdat, 1986. - 45 s.

8. Metodika Gosudarstvennogo sortoispytanija sel'skohozjajstvennyh kul'tur. Vyp. 2, M.: Kolos, 1971. 189 s.

9. Agrohimicheskie metody issledovanija pochv. - M.: Nauka, 1975. - 656 s.

10. Arinushkina, E.V. Rukovodstvo po himicheskomu analizu pochv / E. V Arinushkina. - M.: Izd-vo MGU, 1970. - 487 s. 